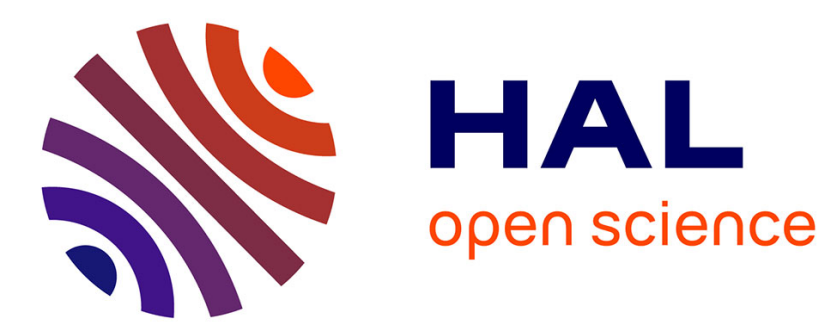

\title{
On the performances of Dynamic Conditional Correlation models in the Sovereign CDS market and the corresponding bond market
}

Saker Sabkha, Christian de Peretti

\section{- To cite this version:}

Saker Sabkha, Christian de Peretti. On the performances of Dynamic Conditional Correlation models in the Sovereign CDS market and the corresponding bond market. Financial and Economic Systems, WORLD SCIENTIFIC (EUROPE), pp.187-212, 2022, 10.1142/9781786349507_0008 . hal-01710398

\section{HAL Id: hal-01710398 \\ https://hal.science/hal-01710398}

Submitted on 15 Feb 2018

HAL is a multi-disciplinary open access archive for the deposit and dissemination of scientific research documents, whether they are published or not. The documents may come from teaching and research institutions in France or abroad, or from public or private research centers.
L'archive ouverte pluridisciplinaire HAL, est destinée au dépôt et à la diffusion de documents scientifiques de niveau recherche, publiés ou non, émanant des établissements d'enseignement et de recherche français ou étrangers, des laboratoires publics ou privés. 



\title{
On the performances of Dynamic Conditional Correlation models in the Sovereign CDS market and the corresponding bond market
}

\author{
Saker Sabkha ${ }^{1,2}$ and Christian de Peretti ${ }^{1}$ \\ ${ }^{1}$ Univ Lyon, University Claude Bernard Lyon 1, \\ Institute of Financial and Insurance Sciences, \\ LSAF-EA2429, F-69007, Lyon, France \\ ${ }^{2}$ Univ of Carthage, Institute of High Commercial Studies, \\ LEFA, Tunis, Tunisia
}

\begin{abstract}
The study of an efficient financial assets' modeling method is still an open hot issue especially during recent crises. Using credit risk data from 33 worldwide countries, this paper investigates the performance of 9 Dynamic Conditional Correlation models taking into account different properties of financial markets (long memory behavior, asymmetry and/or leverage effects...). This comparative study is based on the results of several multivariate diagnostic tests. Findings show that no model outperforms the others in all situations, though, the straightforward DCCGARCH model seems to provide the most relevant estimator parameters. Yet, the innovations distributions assumption significantly impacts the statistical fit of the model. Our work is useful for financial markets' participants so as to making decision in terms of arbitrage, hedging or speculation.
\end{abstract}

\section{JEL Classification}

G11, G12, F02, C58

\section{Keywords}

DCC-class models, Time-varying correlation, Multivariate diagnostic tests, Sovereign credit market. 


\section{Introduction}

The Mathematical formalization of stock market fluctuations has been developed for the first time by Bachelier (1900) who mathematized the speculative values' evolution as a Brownianmotion (Walter, 2013). The probabilistic analysis of the variation of assets' prices proposed by Bachelier (1900) seems not to be valid in the long-run and discords with the efficientmarket assumptions. In fact, The random walk equation that Bachelier (1900) obtained from this model is based on the hypothesis that the instantaneous and nonconstant volatility is independent, linear and follow a Gaussian marginal distribution ${ }^{1}$. De facto, this model presents some shortcomings: Empirical studies easily show that financial times series exhibit kurtosis coefficient in excess rejecting the distribution under normality. Yet, assets' prices in levels are obviously non-stationary and an over-time non-linear dependence is clearly observed between financial returns.

In order to consider for the non-linearity, the non-stationarity and the extreme fluctuations of stock prices, a new class of financial models is proposed by Engle (1982) called Autoregressive Conditional Heteroscedasticity $(\mathrm{ARCH})$. A generalization of this ARCH model (GARCH) is suggested by Bollerslev (1986) enabling for more flexibility and simplicity in the lag structure and the estimation process ${ }^{2}$. Several extensions and restrictive versions of GARCH type have followed allowing to take into account further financial markets' properties and specifications (Engle and Bollerslev, 1986; Engle et al., 1987; Nelson, 1991; Higgins and Bera, 1992; Glosten et al., 1993; Ding et al., 1993; Zakoian, 1994; Sentana, 1995; Hentschel, 1995; Baillie et al., 1996; Bollerslev and Mikkelsen, 1996; Tse, 1998; Klüppelberg et al., 2004; Davidson, 2004).

Numerous applications of the univariate GARCH models to financial data have been done by researchers as well as by finance practitioners. Even though they have been a good toll for financial managers in risk assessment, these volatilities models are inadequate when it comes to estimate a portfolio risk with several and different underlying assets. Because of the interdependence between stock market variables, the estimation of correlations and covariance matrix turns out to be a requisite to financial markets' investors, so they can pursue optimal risk allocation and hedging policies. Thus, portfolio optimization motivates the work of Bollerslev et al. (1988) who propose the first multivariate framework for Generalized Autoregressive Conditional Heteroscedastic models (MV-GARCH). Although it is considered as a considerable theoretical contribution, empirical application of this MV-GARCH - as it is initially proposed - is problematic due to the high-dimension of the parameters and the number of necessary restrictions.

In order to circumvent this estimation complexity, Engle (2002) introduce a new class of multivariate models called Dynamic Conditional Correlation (DCC, hereafter) allowing for correlations to vary over time. This model keeps up with the flexibility of the univariate GARCH models and yet simplifies the parametrization and the empirical estimation. Another DCC-GARCH model is suggested by Tse and Tsui (2002) whereby the correlation computing is also done in two steps: a first step for estimating the univariate GARCH model for each time series and a second step for conditional covariance (see Engle and Sheppard (2001) for further details about technical difference between the two previous models). Engle and Kelly (2012) also propose a time-varying correlation model considering more financial data specifications known as a dynamic equicorrelation model (DECO). In fact, the DCC-DECO model assumes that whenever the time is, correlations' pairwise across markets are equals basing on an arbitrary estimation of the covariance matrix (Engle and Kelly, 2012; Cai et al., 2016) ${ }^{3}$.

\footnotetext{
${ }^{1}$ These are the fractal properties of the random walk and Brownian-motion paths. For more details, see Walter (2013);

${ }^{2}$ A simple $\operatorname{GARCH}(1,1)$ could be an alternative for a long lag length of an ARCH model.

${ }^{3}$ Cai et al. (2016) empirically compare the reliability of dynamic conditional correlation models using both
} 
Based on the aforementioned considerations, DCC models constitute a reliable tool for estimating interconnections between several assets, markets and/or countries. It is obvious thus, that this class of model is used in previous research to investigate financial phenomena: contagion, risk spillover (Lee, 2006; Cai et al., 2016) or co-movement (Coudert and Gex, 2010), given the considerable number of reasons why correlation is an important variable in financial and economic studies.

This paper aims to extend previous works - comparing the performance of GARCH models - to the multivariate dimension ${ }^{4}$. An extensive set of linear and non-linear DCC-GARCH models are estimated: 9 volatility model specifications are represented considering the clustering volatility, the volatility persistence, the dependence between the mean and the conditional variance, the asymmetry of the error distribution, the leverage effect, the long memory property, the slow hyperbolic rate of decay of the volatility persistence, the long-run mean reverting property and the fractionally integrated specifications. These models (GARCH-DCC, IGARCHDCC, EGARCH-DCC, APARCH-DCC, GJR-GARCH-DCC, FIGARCH-DCC, FIEGARCHDCC, FIAPARCH-DCC, HYGARCH-DCC) are estimated using both Engle (2002) and Tse and Tsui (2002) propositions. Yet, results of the models are presented for both Gaussian and Student marginal distribution.

Owing to the noteworthy part played by the credit market during the recent two financial crises, the interest of the scientific community to bonds and to credit derivatives (CDS, CDO, ABX...) is ever-increasing. Modeling multivariate volatilities of credit assets is a high-priority concern among policy makers, portfolio managers and hedge funds. That's why, our studied models are applied to credit risk data (sovereign CDS spreads and the underlying bond spreads) over a relatively long period covering the last two financial crises spanning from January 2006 until April 2014.

Our paper contributes to the extant literature in several ways. First, while there exists a considerable number of studies using the DCC model to estimate multivariate volatilities, the literature comparing the empirical performance of different Dynamic Conditional Correlation models is still not developed, especially when it comes to use the credit assets as an application reference. As far as we are concerned, there is no study comparing 9 dynamic conditional correlation GARCH models for the credit market. Second, the assessment of the interconnectedness between credit markets in an international context puts in forward the fact that countries from different regions present different features. This suggests to improve the standard method abundantly applied to comovement studies by using rather flexible approaches with an individual readjustment for each country and each set of data. Third, studying the multivariate modeling framework in the credit markets presents accurate results since it improves the predictive ability of financial tools in terms of future evolutions in sovereign borrowing conditions.

The rest of the paper is organized as follows: Sections 2 and 3 give some background informations about literature on the comparison of GARCH performances and discuss the methodology approach used in this paper. Section 4 is dedicated to sample description and the descriptive statistics. Empirical results and discussion are covered in section 5 . Section 6 concludes the paper and outlines possible directions for future work.

\footnotetext{
conventional DCC and DECO estimates.

${ }^{4}$ We extend the work of Fantazzini (2011) on the univariate GARCH models and we transmit the same idea to the multivariate volatility models
} 


\section{Literature review}

Unlike volatility models ${ }^{5}$, not much studies has been conducted to assess the performance of the multivariate GARCH-type models. The few works dealing with the time-varying correlation are only interested in straighten out the model's shortcomings by developing some extensive forms taking into account more financial data features.

Evaluating the conditional covariance of 100 companies' assets from the S\&P 500 and the Dow Jones American indices, Engle and Sheppard (2001) develop a framework where the timevarying correlation converges easily and presents strong estimation. Authors propose a simplified method in which correlation coefficients are estimated through two steps ${ }^{6}$ and give some theoretical and empirical evidences of the estimator consistency. In a more theoretical framework, Degiannakis and Xekalaki (2004) summarize the existing literature on ARCH processes and present the most useful multivariate Autoregressive Conditional Heteroscedasticity models, their respective properties and the different estimating techniques.

Using daily 45 stock returns from the DAX and the FTSE, Hafner and Franses (2003) propose a generalized form of the DCC model that controls for heterogeneity. Results show that the GDCC has a superior performance and better fits financial data. One of the DCC issues discussed by Billio et al. (2006), is the restrictive hypothesis of mutual dynamics between different class of assets. Authors propose a flexible Dynamic Conditional Correlation model (fDCC) where each group of assets is allowed to have a different dynamics. By applying the fDCC to three sectors from the Italian stock market, they show that this model provides a better portfolio allocation with a lesser risk and a greater yield. Furthermore, Billio and Caporin (2009) generalize the DCC and the fDCC model and propose a Quadratic Flexible DCC model allowing for interaction between assets' correlations.

Based on a monte carlo simulation, Hafner and Reznikova (2012) study the performance of the estimators of the DCC and the consistent DCC models. Authors find some estimation bias in large sample size and show that the shrinkage technique, as an alternative to the maximum likelihood, can be a solution. Through a theoretical study, Caporin and McAleer (2013) studies the estimating and forecasting limits of the time-varying covariance and correlation models. Among the ten discussed shortcomings, the authors argue that the variance misspecification - due to some financial markets properties (leverage and asymmetry effects) - leads to biased correlation estimator parameters. This research line if followed by Boudt et al. (2013) who propose an extensive form of the DCC model (BIP-cDCC) to overcome the forecasting issue. Application of this new class of models to the exchange rate returns of the euro and the yen against the dollar show that the BIP-cDCC outperforms the standard DCC in terms of forecasting.

In the same context, Aielli (2013) discusses a particular limit of the DCC model and argue that the second stage estimator is biased leading to inappropriate conclusions. Application to simulated and real data show that the alternative model (cDCC) is more consistent with slightly better forecasting performances.

More recently, García de la Fuente et al. (2014) propose an extension of the DCC model that takes into account the non-normality features of financial time series while modeling DCC models. A Bayesian DCC with multivariate skew-slash distribution is applied to simulated data and real data sets from three worldwide stock market indices (CAC40, DAX, Nikkei). Authors show that even though this new class of model allows a better capture of the slight skewness and the high kurtosis characterizing stock returns, it doesn't outperform the standard normal-distributed DCC model. Moreover, Cai et al. (2016) compare the estimators' accuracy

\footnotetext{
${ }^{5}$ See Bollerslev et al. (1992) for a complete theoretical and empirical survey on the use of univariate ARCH processes in financial studies.

${ }^{6}$ More details about the two stages estimation method are given in the next section.
} 
of the dynamic conditional correlation and the dynamic equicorrelation (DECO) ${ }^{7} \mathrm{MGARCH}$ on 9 stock markets from East Asia nd the USA during the Global financial crisis. Results of the DECO model are consistent and confirms those of the standard DCC.

\section{Methodology}

Even though they have been abundantly developed and examined in the theoretical and empirical literature, several correlation models are so sophisticated and over-parameterized with a complicated optimization making them very few used by practitioners. Unlike these models, the DCC nonlinear model proposed by Engle (2002) and Tse and Tsui (2002) is a more reliable estimator of correlation with a limited number of parameters to estimate and an easiest estimation method. The flexibility of this new class of model lies on the fact that the estimation needs to go through two-steps process: the conditional volatility of each time series is estimated from a traditional univariate GARCH model in the first step, then in the second step, the multivariate conditional volatility is estimated using the Quasi-Maximum Likelihood function.

\subsection{Marginal volatility processes: univariate ARCH-type models}

As an extension of the ARCH model proposed by Engle (1982), Bollerslev (1986) propose a generalized ARCH model given by:

$$
\begin{gathered}
x_{i, t}=\mu_{i, t}+a_{i, t} \quad / \quad a_{i, t}=\sigma_{i, t} \varepsilon_{i, t}, \quad \varepsilon_{i, t} / \mathcal{F}_{t-1} \rightsquigarrow \mathcal{N}(0,1) ; \\
\sigma_{i, t}^{2}=E\left(x_{i, t} / \mathcal{F}_{t-1}\right)=\alpha_{i, 0}+\sum_{k=1}^{q} \alpha_{i, k} a_{t-1}^{2}+\sum_{h=1}^{p} \beta_{i, h} \sigma_{t-1}^{2} .
\end{gathered}
$$

with $x_{t}$ is a time series, $i$ is a given country from the sample and $\mu_{t}$ and $\sigma_{t}$ are respectively conditional mean and conditional volatility. To satisfy the positive-definite condition, some restrictions are imposed: $p>=0, q>0, \alpha_{k}>=0$ for $k=1 \ldots q, \beta_{h}>=0$ and $\alpha_{0}>=0$ for $h=1 \ldots p$.

For sake of simplicity and suitability, only models with process orders ( $p$ and $q$ ) equal to 1 are estimated. In fact, the simplest GARCH $(1,1)$ specification is the most useful and fitted for financial time series (Bollerslev, 1986; Wei et al., 2010).

The GARCH(1,1) process, as proposed by Bollerslev (1986) is given by the following formula:

$$
\sigma_{i, t}^{2}=\alpha_{i, 0}+\alpha_{i, 1}+\alpha_{i, 1} a_{t-1}^{2}+\beta_{i, 1} \sigma_{i, t-1}^{2} .
$$

Furthermore to the previous model restrictions, $\alpha_{1}$ and $\beta_{1}$ parameters must satisfy the condition of $\alpha_{1}+\beta_{1}<1$ to comply with the stationarity in the broad sense.

A more restrictive version of the GARCH $(1,1)$ is proposed by Engle and Bollerslev (1986) where the equivalent of the unit root in the mean is included in the variance so we can handle for the stationarity of the variance. The Integrated GARCH $(1,1)$ takes into account the persistence of conditional volatilities ${ }^{8}$. The main difference with the $\operatorname{GARCH}(1,1)$ is that the IGARCH require the parameters $\alpha_{1}$ and $\beta_{1}$ to respect the equality of $\alpha_{1}+\beta_{1}=1$. Thus, the IGARCH $(1,1)^{9}$ can be written as follows:

$$
\sigma_{i, t}^{2}=\alpha_{i, 0}+\alpha_{i, 1} a_{t-1}^{2}+\left(1-\alpha_{i, 1}\right) \sigma_{i, t-1}^{2} .
$$

\footnotetext{
${ }^{7}$ The DECO-MGARCH model, as proposed by Engle and Kelly (2012), supposes that the time-varying conditional correlation is equal between markets (or assets) whatever the time is.

${ }^{8}$ Today's shocks on a financial asset (future contracts for example) have a significant impact on the conditional volatility several periods in the future.

${ }^{9}$ The IGARCH$(1,1)$ is equivalent to the Exponentially Weighted Moving Average (EWMA) model developed by Morgan (1996).
} 
Besides the aforementioned linear models, there exist some nonlinear GARCH-class of models taking into account the other financial markets properties. The Exponential GARCH, as proposed by Nelson (1991), is one of these models that accounts for the leverage effect and the asymmetry of the error distribution. While the nonnegativity of linear GARCH model is ensured by several parameters restrictions, the EGARCH model proposes another formulation allowing for a positive volatility without any restrictive constraints. The EGARCH $(1,1)$ is expressed as follows:

$$
\begin{array}{r}
\ln \left(\sigma_{i, t}^{2}\right)=\alpha_{i, 0}+\alpha_{i, 1-1} \ln \left(\sigma_{i, t}^{2}\right)+\beta_{i, 1} g\left(\varepsilon_{i, t-1}\right) \\
\text {, where } \quad g\left(\varepsilon_{t}\right)=\theta \varepsilon_{t}+\gamma\left[\left|\varepsilon_{t}\right|-E\left(\left|\varepsilon_{t}\right|\right)\right] .
\end{array}
$$

The asymmetric relation between assets' fluctuation and volatility changes is depicted by the $\theta$ and $\gamma$ representing respectively the the sign and the magnitude of $\varepsilon_{t}$.

Glosten et al. (1993) propose a model that allows the sign and the amplitude of the innovations $\left(\varepsilon_{t}\right)$ to affect separately the conditional volatility. The asymmetric leverage effect ${ }^{10}$ is represented in the following formulation of the GJR-GARCH $(1,1)^{11}$ model:

$$
\sigma_{i, t}^{2}=\alpha_{i, 0}+\alpha_{i, 1} a_{i, t-1}^{2}+\gamma_{i} I_{i, t-1} a_{i, t-1}^{2}+\beta_{i, 1} \sigma_{i, t-1}^{2}
$$

with $I_{t}$ is a dummy variable equals to 0 when $a_{t}$ is positive and 1 otherwise.

The first model accounting for the long-range persistence of financial assets variance is developed by Ding et al. (1993). This asymmetric power ARCH model allows the volatility to be long-memory ${ }^{12}$. The APARCH $(1,1)$ model is:

$$
\sigma_{i, t}^{2}=\alpha_{i, 0}+\alpha_{i, 1}\left(\left|a_{i, t-1}\right|-\gamma_{i} a_{i, t-1}\right)^{\delta}+\beta_{i, 1} \sigma_{i, t-1}^{\delta} .
$$

where $\delta$ depicts the Box-Cox power transformation of the conditional volatility $\left(\sigma_{t}\right)$ and satisfies the condition of $\delta>=0$.

A more flexible class of GARCH models is proposed by Baillie et al. (1996) who introduce a new feature of the unit root for the variance. In fact, the fractionally integrated GARCH model (FIGARCH) highlights the fact that - unlike stationary processes where the persistence of volatility shocks is finite - in unit root processes, the impact of lagged errors occurs at a slow hyperbolic rate of decay. The FIGARCH model allows, thus, to capture the long memory in financial volatility with a complete flexibility regarding the persistence degree. In fact, the FIGARCH $(1, \mathrm{~d}, 1)$ formulation depends on fractional integration parameter $(\mathrm{d})$ as follows:

$$
\sigma_{i, t}^{2}=\alpha_{i, 0}+\left[1-\left(1-\beta_{i}(L)\right)^{-1}(1-\phi(L))(1-L)^{d}\right] a_{i, t}^{2}+\beta \sigma_{i, t-1}^{2} .
$$

with $0<d<1$. When $\mathrm{d}=1$, the $\operatorname{FIGARCH}(1, \mathrm{~d}, 1)$ is equivalent to an $\operatorname{IGARCH}(1,1)$ where the persistence of conditional variance is supposed to be complete, while when $d=0$, it is rather equivalent to a $\operatorname{GARCH}(1,1)$ and no volatility persistence is taken into consideration. $\mathrm{L}$ is the lag operator and $(1-L)^{d}$ is the financial fractional differencing operator.

Other ARCH formulations are extended to the fractionally integrated GARCH, including asymmetric leverage effect presented in the EGARCH model. Bollerslev and Mikkelsen (1996) propose a new class of model combining characteristics of the FIGARCH and the EGARCH models so-called FIEGARCH (p,d,q). Financial assets' volatilities are, thus, better explained

\footnotetext{
${ }^{10}$ Positive and negative financial shocks revamp asymmetrically the variance. Furthermore, bad news (shocks) generate greater volatility than good news.

${ }^{11}$ The volatility's different reactions to signs and sizes of past innovations are also suggested in the Threshold Heteroskedastic model (TGARCH) of Zakoian (1994). The major difference is that in the TGARCH model the conditional standard deviation $\left(\sigma_{t}\right)$ is considered rather than the conditional variance $\left(\sigma_{t}^{2}\right)$.

${ }^{12}$ The autocorrelation function of time series returns decreases gradually.
} 
and depicted by a mean-reverting fractionally integrated process. The FIEGARCH(1,d,1) model is written as follows:

$$
\ln \left(\sigma_{i, t}^{2}\right)=\alpha_{i, 0}+\phi(L)^{-1}(1-L)^{-d}[1+\psi(L)] g\left(\varepsilon_{i, t-1}\right) .
$$

where $\phi(L)$ and $\psi(L)$ are lag polynomials, and - as in the $\operatorname{EGARCH}(1,1)^{13}-g\left(\varepsilon_{t}\right)$ is a quantization function of information flows such as:

$$
g\left(\varepsilon_{t}\right)=\theta \varepsilon_{t}+\gamma\left[\left|\varepsilon_{t}\right|-E\left(\left|\varepsilon_{t}\right|\right)\right] .
$$

An extension of the conventional fractionally integrated GARCH model is proposed by Tse (1998) so-called FIAPARCH $(1, \mathrm{~d}, 1)$. The new approach combines the long-range dependencies feature and the asymmetric impact of lagged positive and negative shocks on future volatilities in one fractionally integrated model. The FIAPARCH $(1, \mathrm{~d}, 1)$ is written as follows:

$$
\sigma_{i, t}^{\delta}=\alpha_{i, 0}(1-\beta)^{-1}+\left[1-(1-\beta(L))^{-1} \phi(L)(1-L)^{d}\right]\left(\left|a_{i, t}\right|-\gamma a_{i, t}\right)^{\delta} .
$$

More recently, another linear GARCH model, called hyperbolic GARCH (HYGARCH) is proposed by Davidson (2004) who argues that the impact of lagged errors on the conditional variance discloses near-epoch dependence feature. The main contribution of this model is that the fractional integration parameter is negative (-d) instead of positive and that $\mathrm{d}$ increases rather when it approaches zero ${ }^{14}$. The statistical properties included in the HYGARCH make it the most successful and used approach by financial practitioners in modeling time series volatilities. The HYGARCH $(1, \mathrm{~d}, 1)$ is defined under the following formulation:

$$
\sigma_{i, t}^{2}=\alpha_{i, 0}+\left[1-(1-\beta(L))^{-1}(1-\phi(L))\left[1+\alpha\left((1-L)^{d}-1\right)\right]\right] a_{i, t}^{2} .
$$

As mentioned before, The 9 GARCH-class models, above cited, are estimated in the first step through a univariate process to capture the apparent conditional univariate standard deviations. Then, a multivariate process is estimated in the second step so we can have the conditional bivariate volatilities (conditional correlations).

\subsection{Joint volatility processes: multivariate ARCH-type models}

In the second step, the multivariate specification is introduced to each one of the GARCHclass models in order to estimate the bivariate dynamic conditional correlations. Following the propositions of Engle (2002) and Tse and Tsui (2002), the DCC model is defined as a time varying structure:

$$
\operatorname{Var}\left(x_{t} / \mathcal{F}_{t-1}\right)=\sigma_{t}^{2}=\Omega_{t}=D_{t} H_{t} D_{t} .
$$

where $\mathcal{F}_{t-1}$ is the information set available at the time (t-1). $D_{t}$ is a diagonal matrix $N \times$ $N$ such as $D_{t}=\operatorname{diag}\left\{\operatorname{sigma}_{i i, t}\right\}=\operatorname{diag}\left(\sigma_{11, t} \ldots \sigma_{N N, t}\right), \sigma_{N N, t}$ is the conditional standard deviation obtained from the univariate models. $H_{t}$ is the time-varying correlation matrix of the standardized residuals $\varepsilon_{t}$ ( of $x_{t}$ ).

Engle (2002) and Tse and Tsui (2002) propose two DCC models presenting some similarities and divergences. For Engle (2002),

$$
H_{t}=\operatorname{diag}\left(q_{11, t}^{-1 / 2} \ldots q_{N N, t}^{-1 / 2}\right) Q_{t} \operatorname{diag}\left(q_{11, t}^{-1 / 2} \ldots q_{N N, t}^{-1 / 2}\right) .
$$

\footnotetext{
${ }^{13}$ When the memory parameter, $\mathrm{d}=0$, the $\mathrm{FIEGARCH}$ formulation is equivalent to the conventional EGARCH $(1,1)($ FIEGARCH $(1,0,1) \simeq \operatorname{EGARCH}(1,1))$.

${ }^{14}$ When $\mathrm{d}$ of the HYGARCH is positive, it is considered as a unit root process.
} 
where $\overline{q_{i j}}=\overline{\rho_{i j}}\left(\overline{\rho_{i j}}\right.$ is the unconditional correlation between $\varepsilon_{i, t}$ et $\left.\varepsilon_{j, t}\right)$. $Q_{t}$ is symmetric covariance $N \times N$ matrix that can be written as follows:

$$
Q_{t}=\overline{Q_{i j}}(1-\alpha-\beta)+\alpha\left(\varepsilon_{t-1} \varepsilon_{t-1}^{\prime}\right)+\beta Q_{i j, t-1} .
$$

with $\bar{Q}$ is a symmetric time invariant unconditional correlation matrix. $\alpha$ et $\beta$ parameters are postive and respect the constraint of $\alpha+\beta<1$. The bivariate dynamic conditional correlation coefficient of Engle (2002) is, thus, defined as:

$$
\rho_{12, t}=\frac{\overline{q_{12}}(1-\alpha-\beta)+\alpha\left(\varepsilon_{1, t-1} \varepsilon_{2, t-1}\right)+\beta q_{12, t-1}}{\sqrt{\left(\overline{q_{11}}(1-\alpha-\beta)+\alpha \varepsilon_{11, t-1}^{2}+\beta q_{11, t-1}\right)\left(\overline{q_{22}}(1-\alpha-\beta)+\alpha \varepsilon_{22, t-1}^{2}+\beta q_{22, t-1}\right)} .}
$$

For Tse and Tsui (2002), $H_{t}=\{\rho i j, t\}$ is assumed to follow a univariate GARCH process and is obtained from the recursion of:

$$
H_{t}=\left(1-\theta_{1}-\theta_{2}\right) H+\theta_{1} H_{t-1}+\theta_{2} \Xi_{t-1}
$$

where the parameters $\theta_{1}$ and $\theta_{2}$ are supposed to satisfy the non-negativity constraint and the inequality $\theta_{1}+\theta_{2}<=1$. $\mathrm{H}$ is a symmetric time invariant $N \times N$ with $\rho_{i i}=1$ (a unit diagonal element. $\Xi_{t-1}$ is the correlation matrix of the lagged standardized residuals $\varepsilon_{t}$ such as $\varepsilon_{i, t}=\frac{a_{t}}{\sigma_{i, t}}$. Since $\Xi_{t-1}$ depends on the lagged residuals, and analogously to the $x_{t-1}^{2}$ in the GARCH $(1,1)$ representation, $\Xi_{t-1}$ can be specified by the following formula:

$$
\Xi_{i j, t-1}=\frac{\sum_{m=1}^{M} \varepsilon_{i, t-m} \varepsilon_{j, t-m}}{\sqrt{\left(\sum_{m=1}^{M} \varepsilon_{i, t-m}^{2}\right)\left(\sum_{m=1}^{M} \varepsilon_{j, t-m}^{2}\right)}}, 1 \leq i<j \leq N \leq M .
$$

$N \leq M$ is a necessary condition for $\psi_{t-1}$ and $H_{t}$ to be nonnegative definite. Thus, in the bivariate case, the conditional correlation coefficient of Tse and Tsui (2002) is defined as:

$$
\rho_{12, t}=\left(1-\theta_{1}-\theta_{2}\right) \rho_{12}+\theta_{1} \rho_{12, t-1}+\theta_{2} \frac{\sum_{s=1}^{S} \varepsilon_{1, t-s} \varepsilon_{2, t-s}}{\sqrt{\left(\sum_{s=1}^{S} \varepsilon_{1, t-s}^{2}\right)\left(\sum_{s=1}^{S} \varepsilon_{2, t-s}^{2}\right)}} .
$$

In this paper, dynamic conditional correlation coefficients are estimated using both models proposed by Engle (2002) and Tse and Tsui (2002): For each of the estimated model, time series are assumed to follow an $\mathrm{AR}(1)$ process with a normal and t-student marginal distributions. Models' performances comparison is made upon the value of the Akaike information criterion (AIC) and some multivariate diagnostic tests: Vector normality test and Hosking's Multivariate Portmanteau Statistics on standardized residuals (and on squared standardized residuals) are used to investigate the reliability of the multivariate GARCH specifications.

\section{Data}

The models detailed above are estimated using daily price changes data from the credit market of 33 countries worldwide belonging to four different economic status (low economic growth, developed countries, newly industrialized countries and emerging countries). DCC models are estimated on both credit spreads of sovereign CDS market and the corresponding government bond market, on a period spanning from January, $2^{\text {nd }} 2006$ until April, $3^{\text {th }}$ 2014. CDS spreads and bond yields are extracted from Bloomberg®and Thomson Reuters®.

During the studied period (2006-2014), the world economy has been affected by two major crises - namely the Global Financial Crisis and the European Debt Crisis - and the state borrowing costs greatly fluctuated whatever the country's economic level is or its geographical 
position. Thus, evaluating and comparing the performances of multivariate volatility models is particularly relevant during this period.

For sake of homogeneity, bond yields are transformed into spreads regarding the risk-free interest rate. Several studies interest in the issue of the appropriate choice of this riskless rate. A first strand of the literature suggests the use of the US treasury yield (Longstaff et al., 2005) or the swap rate of the same maturity (Blanco et al., 2005). Another strand promotes the use of the bond rate issued by the country considered to be the least risky of the zone (government bond yield curves of Deutsch Bundesbank, the Federal Reserve Board and the bank of England) (Norden and Weber, 2009; Gilchrist and Mojon, 2016). In this paper, the 5 year German federal government bond is chosen as a reference rate for European countries, and the United States sovereign bonds for American and Asian countries. In order to not reduce ou sample, for Germany, euro-area generic bond is used as a benchmark yield, and the US Treasury Zero-Coupon Yield Curve for the United States.

Descriptive statistics are provided in Table 1. CDS and Bond spreads exhibit similar statistical properties. The average daily spreads are almost always positive (except for Germany, USA and Japan where the Bond spreads' mean is negative). Negative credit spreads can be explained by the fact that during recessions markets participants are willing to pay government for riskless investments, making bonds of some countries (Germany among others) issued with negative yields (Dolvin, 2012). This phenomenon can be caused, likewise, by a temporary liquidity factors (Beber et al., 2009; Bhanot and Guo, 2011). Another explanation is that these negative spreads are due to a mis-choice of the risk-free rate. The high levels of standard deviations show that our data is widely spread and not centered around the mean.

The Jarque-Bera test confirms the non-normality of the data distribution at the $1 \%$ significance level. Theses findings are reaffirmed but the significant excess kurtosis and the positive skewness coefficients. As expected, the Augmented Dickey-Fuller test confirms the null hypothesis of the unit-root presence. Both CDS spreads and bond spreads are non-stationary. The ARCH-LM test and the Q statistics of Ljung-Box both confirm the presence of ARCH effect and reject the null hypothesis of no serial correlation in the CDS and Bond spreads. 


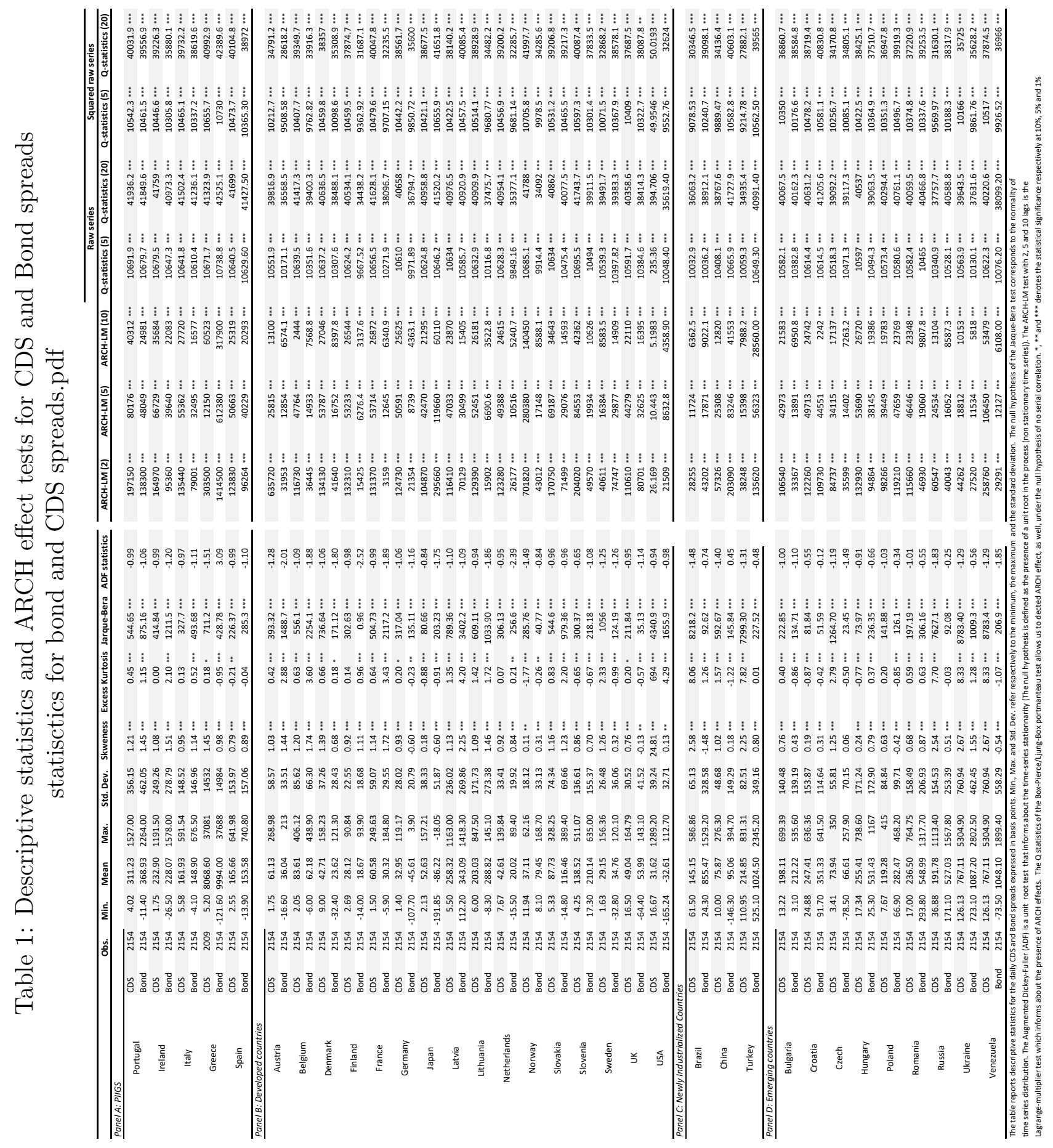




\section{Empirical results}

For each of the 33 countries composing our sample, 9 DCC models ares estimated following Engle (2002) and Tse and Tsui (2002). Results of the conditional multivariate volatility models are not reported here due to space limits but are available upon request. Table 2 reports diagnostic checking tests for different models of some chosen countries. 


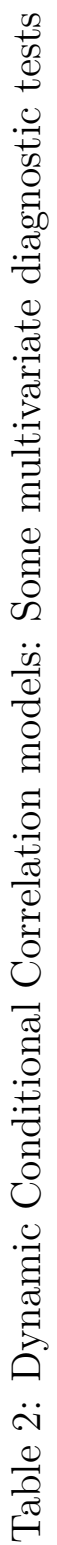

(1)

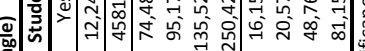

言

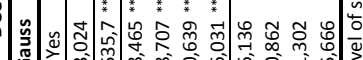

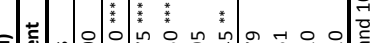

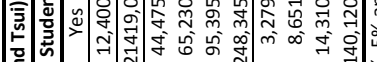

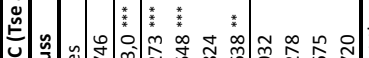

$\overline{\overline{\mathrm{v}}}$

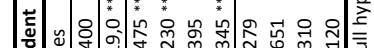

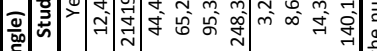

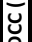

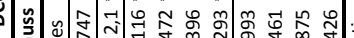

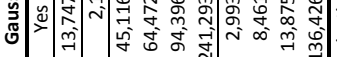

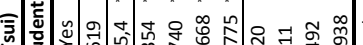

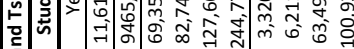

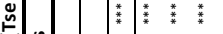

$\breve{b}$

高

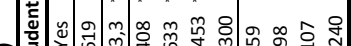

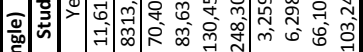

(1)

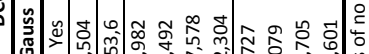

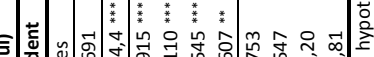

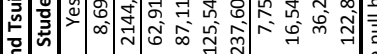

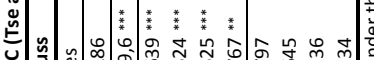

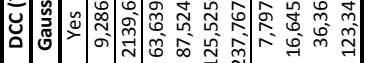

旁

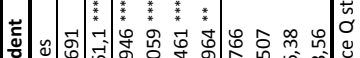

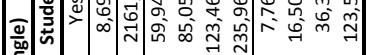

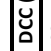

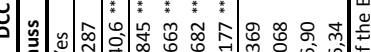

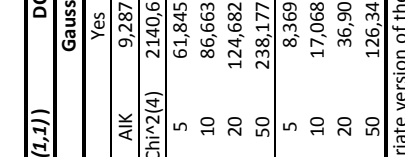

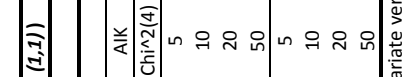

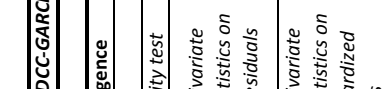

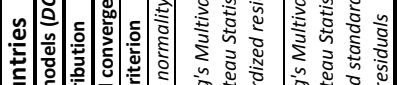

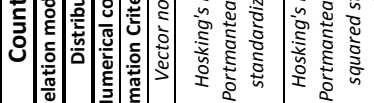

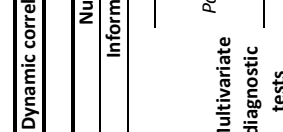

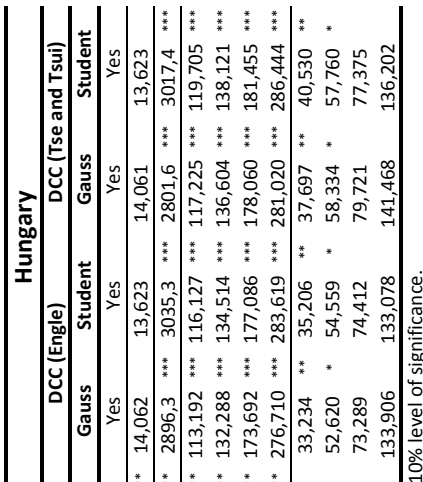

$\widehat{\overline{\mathbf{n}}}$

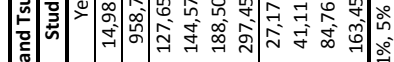
品

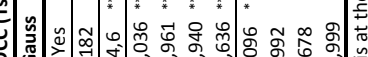

䓂

.

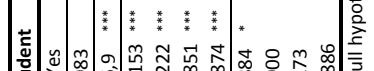

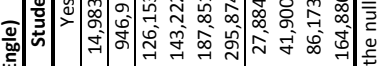

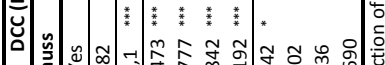

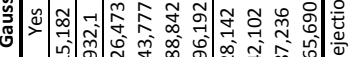
㖣

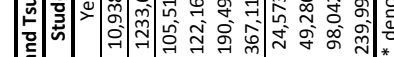

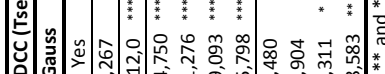
$\frac{7}{ \pm}$

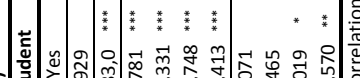

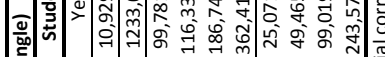

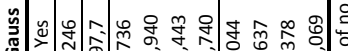

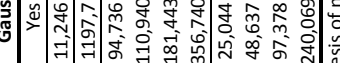

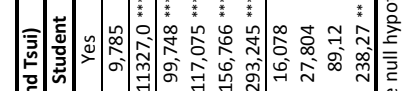
管

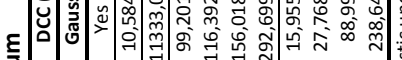

这)

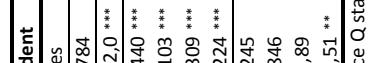

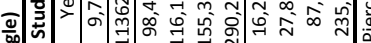

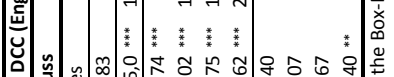

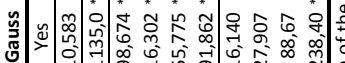

氛 焉

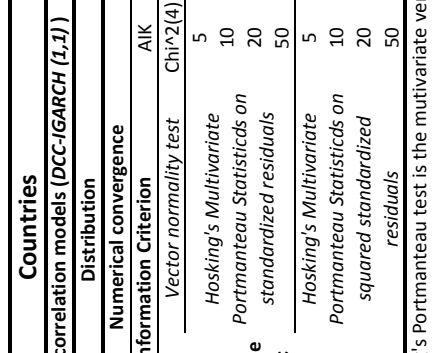

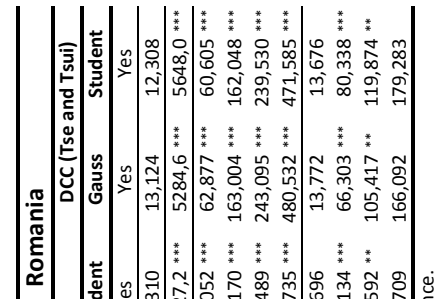

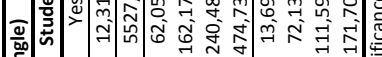
产

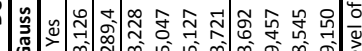

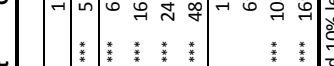

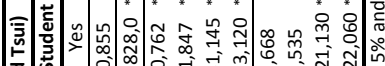
管

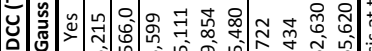

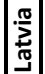
J

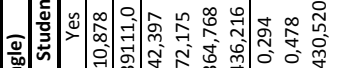
幽 $\breve{\Delta}$ -

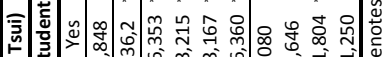

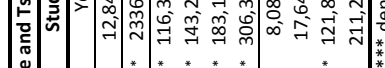

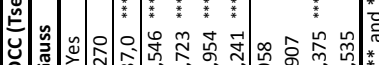

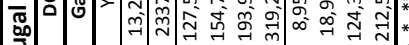
힝

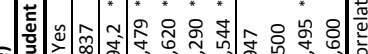

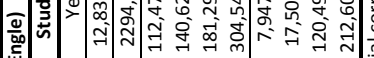

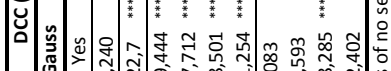

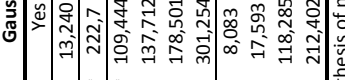

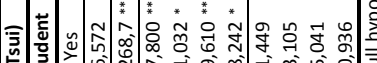

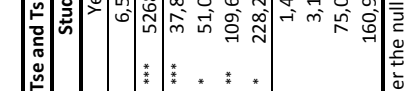

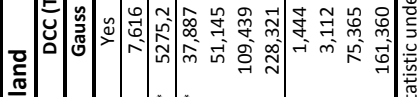
$\frac{5}{4}$

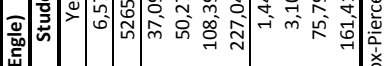

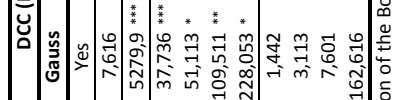

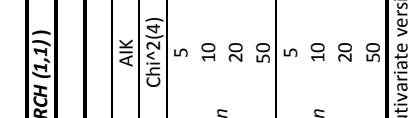

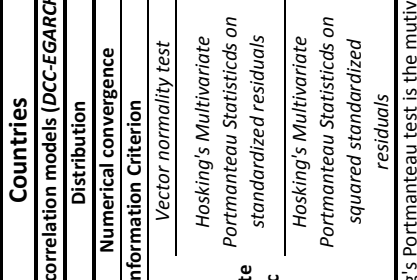

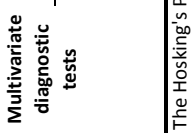




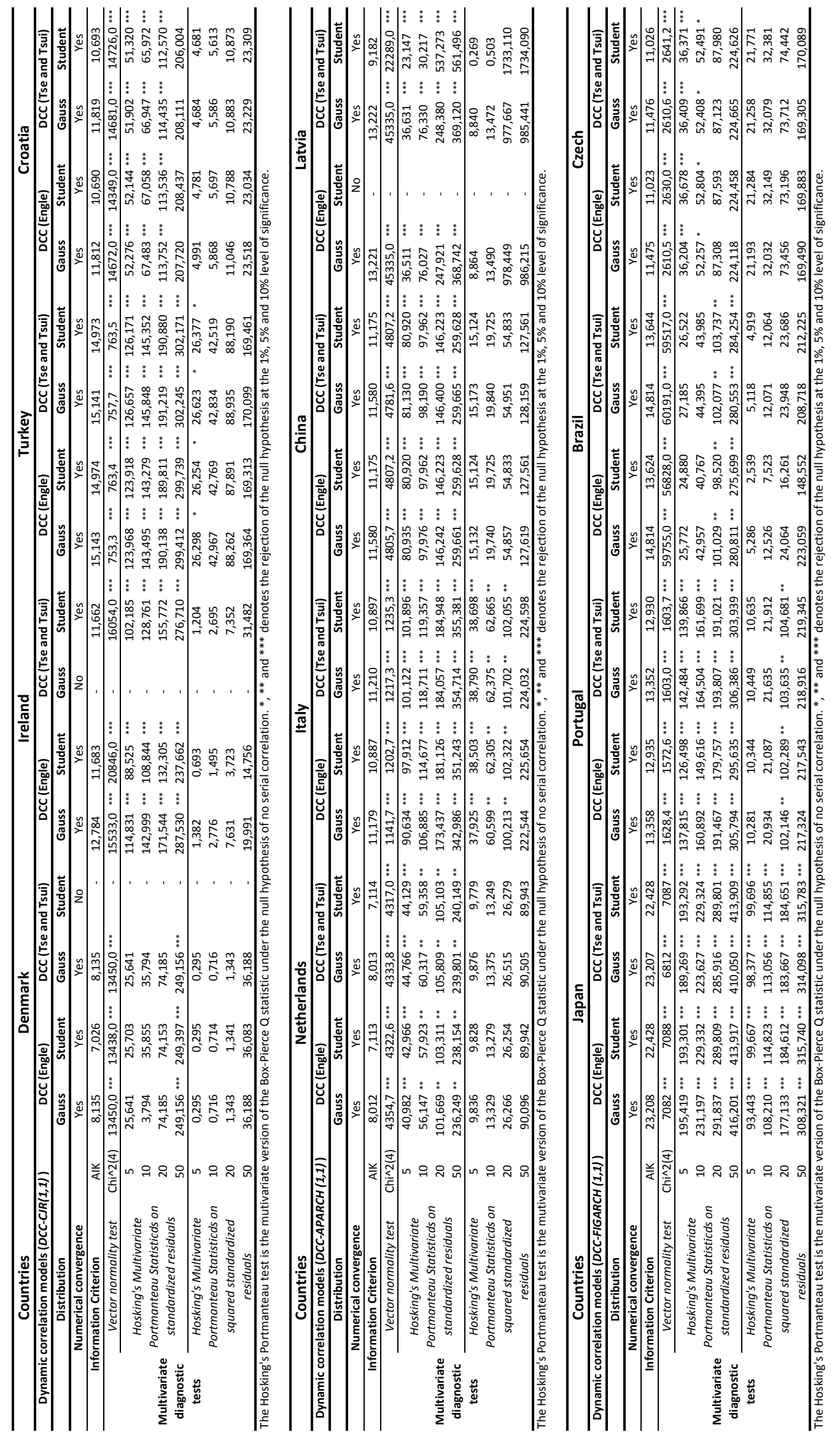




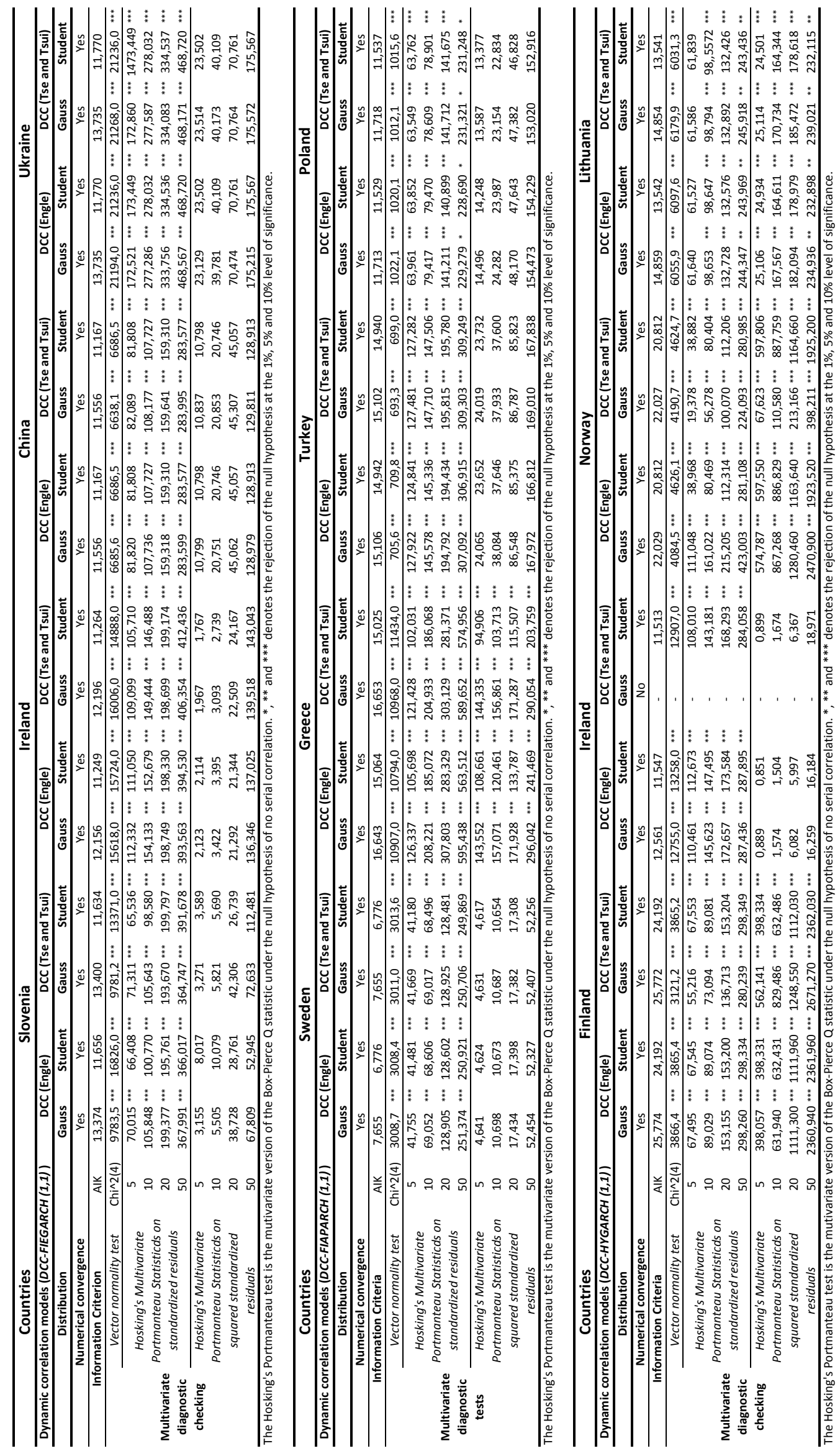


DCC-FIGARCH, DCC-FIAPARCH and DCC-HYGARCH are the most difficult models to estimate with miss-convergences in at least 14 among the 33 countries. At the opposite, the models that great perform as to strong numerical convergence and computing-time delay are the DCC-GARCH, the DCC-IGARCH and the fractional model DCC-FIEGARCH. Among fractionally integrated models, the DCC-FIAPARCH is the most miss-specified model with a non-convergence in 18 countries.

Taking into account different financial markets' properties (long memory behavior, shock persistence and asymmetric leverage effects...) does not necessarily improve the models performances. The complexity of the model's statistical specifications can not be justified in all cases leading to inconsistent and inaccurate estimator parameters. However, the opposite may be true since the more the model is over-parametrized, the more its computation and its convergence are complicated.

The Akaike information criterion (AIK) doesn't allow us to select only one optimal model. AIK results of the studied models are mitigated across each country of the sample. The only conclusion that can be drawn, is that the information criterion is almost always lower for the student marginal distribution. Without knowing the facts, allowing the data to follow a student rather than a Gaussian distribution law make a better fit of dynamic conditional correlation models. This confirms the heavy tails and the slightly skewed data distributions suggested by te Jarque-Bera preliminary test.

The vector normality tests reject the null hypothesis of the linearity of combinations between innovations of all models and for all countries under study. This means that combinations between CDS and bond spreads have too many extreme values (significant excess kurtosis) and a fat-tailed distribution. The assumption of a multivariate student marginal distribution of our time series is once again preferred.

Results of the diagnostic tests on the standardized residuals show that there is an obvious misspecification in the conditional mean equations of all the estimated models (The multivariate Q-statistics is almost always significant at $5 \%$ whatever the number of lags is). One explanation is that 1 is not the optimal order number of $\mathrm{AR}($.$) suggesting a more persistent (less quickly)$ shocks' integration in the credit markets. The autoregressive terms can be allowed to vary from zero to three so we can better control for the serial correlation of CDS and bond spreads times series.

Misspecification are also detected in the conditional multivariate variance of some DCC models. ARCH effects are still present in the squared standardized residuals even after controlling for the heteroscedasticity. The best fitted models, in terms of autocorrelation in the time series, are DCC-GARCH and the DCC-FIEGARCH. The Hoskings' multivariate portmanteau statistics, up to $10^{t h}, 20^{\text {th }}$ and $50^{\text {th }}$ order of lags, accept the null hypothesis of no correlation in the sovereign credit assets. However, in the same context, the APARCH doesn't perform good with serial correlations detected in all combinations of innovations for all countries.

The last striking finding is that the Engle's DCC and Tse and Tsui's DCC present very close results and no significant divergence is detected. Focusing on the DCC plots of the Engle and the Tse and Tsui (Fig. 1 and Fig. 2), it is clearly seen that the correlation's evolution dynamic of both estimation techniques is almost the same for all the countries (Except for Japan, Denmark, Norway and China). 

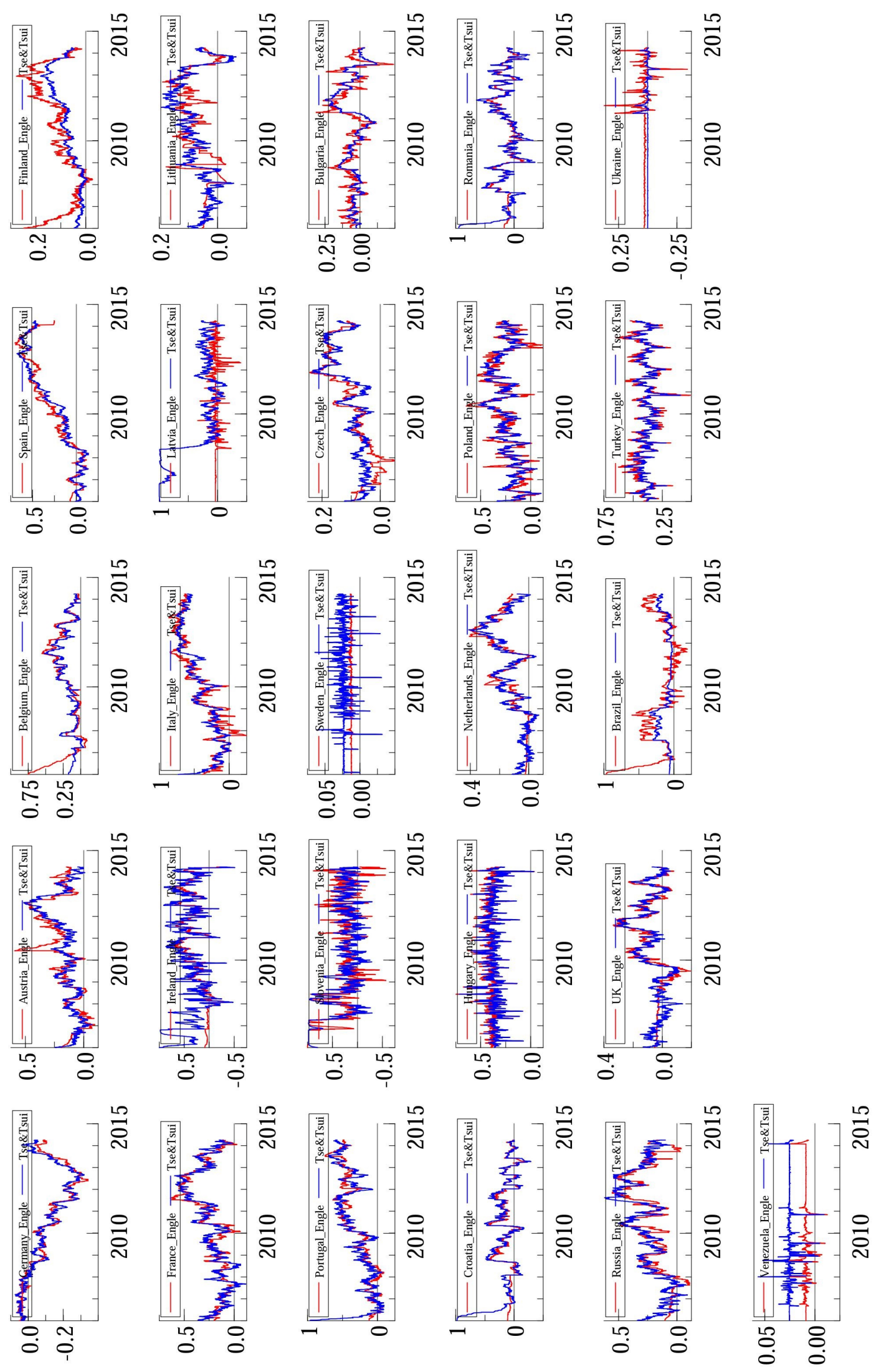

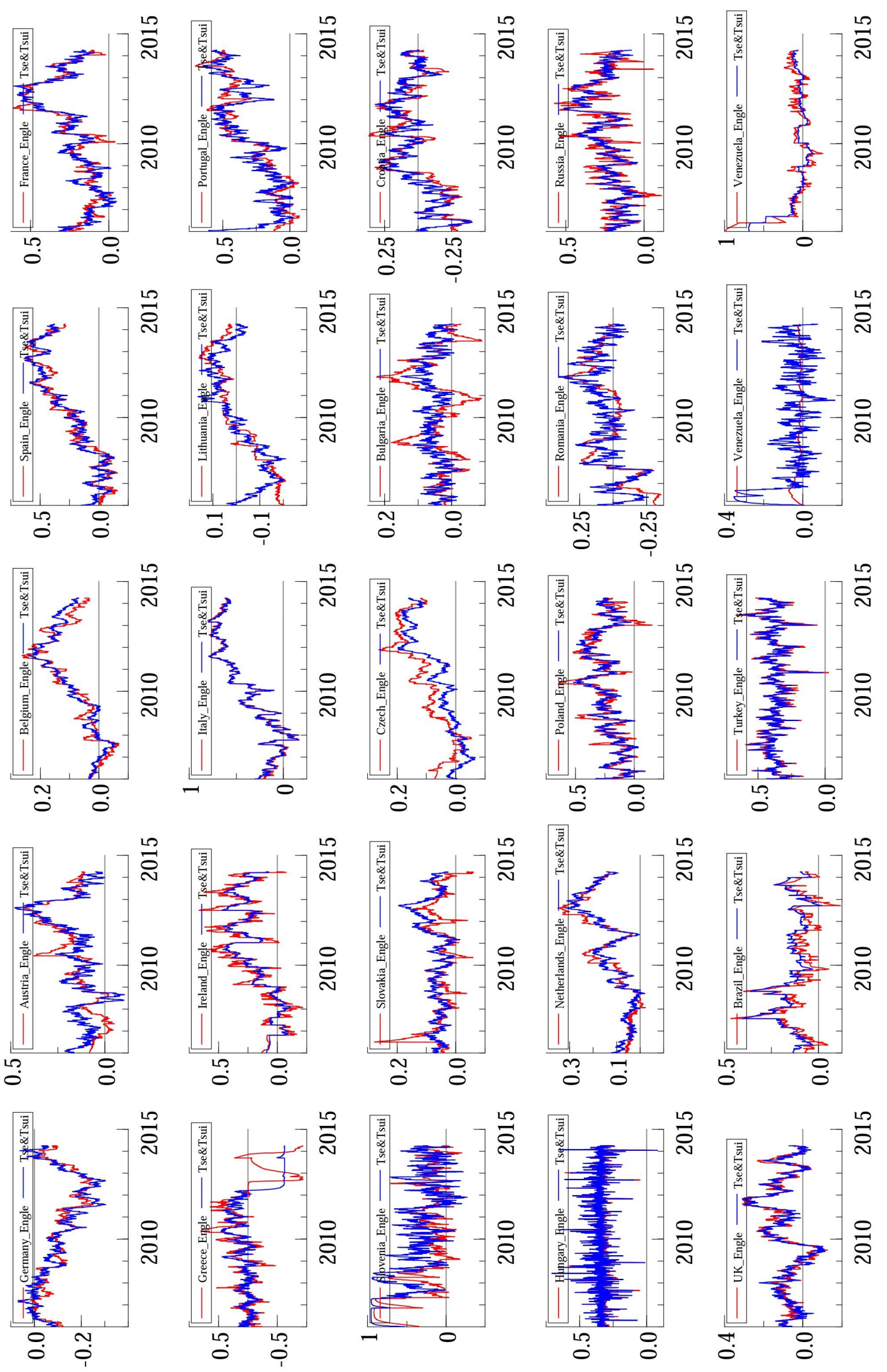


\section{Conclusion}

This paper aimed to assess the performances of 9 Dynamic Conditional Correlation models. Using sovereign CDS and bond data, DCC-GARCH, DCC-IGARCH, DCC-EGARCH, DCC-GJR, DCC-APARCH, DCC-FIGARCH, DCC-FIEGARCH, DCC-FIAPARCH, DCC-HYGARCH are estimated, allowing to take into account different financial markets' properties such as the leverage effect, the asymmetric reaction to good and bad news and long-range persistence. The performance comparison being made upon the information criteria and several multivariate diagnostic tests, a certain number of conclusions can be drawn.

First, although the CDS and bond data exhibit long memory behavior, shock persistence and asymmetric leverage effects, models taking into account all these specifications does not provide better estimation results. The straightforward DCC-GARCH model seems to provide the most relevant estimator parameters in terms of diagnostic tests. Second, the innovations distributions assumption significantly impacts the statistical fit of the model since the information criterion is almost always lower for models with student marginal distribution compared to models with Gaussian distribution. Third, all models present serial correlation in the standardized residuals indicating a misspecification in the conditional mean equation. This is might be due low order of the AR process and to the persistence of shocks in worldwide credit markets. In addition, a constantly time-varying and different hedging positions should be taken across countries that present dissimilar financial characteristics.

Since modeling correlation is of a paramount importance in assessing diversification risk, in dynamic asset pricing theory and in optimization of portfolio allocation, the economic implication of our findings concerns particularly policymakers, financial practitioners and financial markets participants generally. Even though no model clearly outperforms all the others, our results show that the basic DCC-GARCH and the DCC-FIEGARCH model seems to better fit the studied data. However, results are mitigated and differ from one country to another which implies that no multivariate volatility model should be selected in an arbitrary way. The model selection should rather be based on the particular features of the data used and the countries composing the sample studied.

Our research line can be pursued in several ways. First, a further investigation on the performances of the Dynamic Conditional Correlation models can be done by carrying out a comparative study based of the predictive reliabilities rather than on diagnostic tests as in our case. Second, our study can be generalized to other financial markets, namely the primary equity markets, in order to asses whether the nature of the asset impact the performances of the studied models. Third, since there is a dynamic segmentation in financial markets, it can be interesting to check the robustness of our findings using a different sample from other regions.

\section{References}

Gian Piero Aielli. Dynamic conditional correlation: on properties and estimation. Journal of Business \& Economic Statistics, 31(3):282-299, 2013.

Louis Bachelier. Théorie de la spéculation. Gauthier-Villars, 1900.

Richard T Baillie, Tim Bollerslev, and Hans Ole Mikkelsen. Fractionally integrated generalized autoregressive conditional heteroskedasticity. Journal of econometrics, 74(1):3-30, 1996.

Alessandro Beber, Michael W Brandt, and Kenneth A Kavajecz. Flight-to-quality or flightto-liquidity? evidence from the euro-area bond market. Review of Financial Studies, 22(3): 925-957, 2009. 
Karan Bhanot and Liang Guo. Negative credit spreads: Liquidity and limits to arbitrage. The Journal of Fixed Income, 21(1):32-41, 2011.

Monica Billio and Massimiliano Caporin. A generalized dynamic conditional correlation model for portfolio risk evaluation. Mathematics and Computers in Simulation, 79(8):2566-2578, 2009.

Monica Billio, Massimiliano Caporin, and Michele Gobbo. Flexible dynamic conditional correlation multivariate garch models for asset allocation. Applied Financial Economics Letters, 2(02):123-130, 2006.

Roberto Blanco, Simon Brennan, and Ian W Marsh. An empirical analysis of the dynamic relation between investment-grade bonds and credit default swaps. The Journal of Finance, 60(5):2255-2281, 2005.

Tim Bollerslev. Generalized autoregressive conditional heteroskedasticity. Journal of econometrics, 31(3):307-327, 1986.

Tim Bollerslev and Hans Ole Mikkelsen. Modeling and pricing long memory in stock market volatility. Journal of econometrics, 73(1):151-184, 1996.

Tim Bollerslev, Robert F Engle, and Jeffrey M Wooldridge. A capital asset pricing model with time-varying covariances. Journal of political Economy, 96(1):116-131, 1988.

Tim Bollerslev, Ray Y Chou, and Kenneth F Kroner. Arch modeling in finance: A review of the theory and empirical evidence. Journal of econometrics, 52(1-2):5-59, 1992.

Kris Boudt, Jon Danielsson, and Sébastien Laurent. Robust forecasting of dynamic conditional correlation garch models. International Journal of Forecasting, 29(2):244-257, 2013.

Xiao Jing Cai, Shuairu Tian, and Shigeyuki Hamori. Dynamic correlation and equicorrelation analysis of global financial turmoil: evidence from emerging east asian stock markets. Applied Economics, 48(40):3789-3803, 2016.

Massimiliano Caporin and Michael McAleer. Ten things you should know about the dynamic conditional correlation representation. Econometrics, 1(1):115-126, 2013.

Virginie Coudert and Mathieu Gex. Contagion inside the credit default swaps market: The case of the gm and ford crisis in 2005. Journal of International Financial Markets, Institutions and Money, 20(2):109-134, 2010.

James Davidson. Moment and memory properties of linear conditional heteroscedasticity models, and a new model. Journal of Business 85 Economic Statistics, 22(1):16-29, 2004.

Stavros Degiannakis and Evdokia Xekalaki. Autoregressive conditional heteroscedasticity (arch) models: A review. Quality Technology $\&$ Quantitative Management, 1(2):271-324, 2004.

Zhuanxin Ding, Clive WJ Granger, and Robert F Engle. A long memory property of stock market returns and a new model. Journal of empirical finance, 1(1):83-106, 1993.

Steven D Dolvin. Negative bond yields. 2012.

Robert Engle. Dynamic conditional correlation: A simple class of multivariate generalized autoregressive conditional heteroskedasticity models. Journal of Business E Economic Statistics, 20(3):339-350, 2002. 
Robert Engle and Bryan Kelly. Dynamic equicorrelation. Journal of Business 6 Economic Statistics, 30(2):212-228, 2012.

Robert F Engle. Autoregressive conditional heteroscedasticity with estimates of the variance of united kingdom inflation. Econometrica: Journal of the Econometric Society, pages 987$1007,1982$.

Robert F Engle and Tim Bollerslev. Modelling the persistence of conditional variances. Econometric reviews, 5(1):1-50, 1986.

Robert F Engle and Kevin Sheppard. Theoretical and empirical properties of dynamic conditional correlation multivariate garch. Technical report, National Bureau of Economic Research, 2001.

Robert F Engle, David M Lilien, and Russell P Robins. Estimating time varying risk premia in the term structure: the arch-m model. Econometrica: Journal of the Econometric Society, pages 391-407, 1987.

Dean Fantazzini. Fractionally integrated models for volatility: A review. In Nonlinear Financial Econometrics: Markov Switching Models, Persistence and Nonlinear Cointegration, pages 104-123. Springer, 2011.

Cristina García de la Fuente, Michael P Wiper, Pedro Galeano, et al. Bayesian estimation of a dynamic conditional correlation model with multivariate skew-slash innovations. Technical report, Universidad Carlos III de Madrid. Departamento de Estadística, 2014.

Simon Gilchrist and Benoit Mojon. Credit risk in the euro area. The Economic Journal, 2016.

Lawrence R Glosten, Ravi Jagannathan, and David E Runkle. On the relation between the expected value and the volatility of the nominal excess return on stocks. The journal of finance, 48(5):1779-1801, 1993.

Christian Hafner and Philip Hans Franses. A generalized dynamic conditional correlation model for many asset returns. Technical report, 2003.

Christian M Hafner and Olga Reznikova. On the estimation of dynamic conditional correlation models. Computational Statistics \&5 Data Analysis, 56(11):3533-3545, 2012.

Ludger Hentschel. All in the family nesting symmetric and asymmetric garch models. Journal of Financial Economics, 39(1):71-104, 1995.

Matthew L Higgins and Anil K Bera. A class of nonlinear arch models. International Economic Review, pages 137-158, 1992.

Claudia Klüppelberg, Alexander Lindner, and Ross Maller. A continuous-time garch process driven by a lévy process: stationarity and second-order behaviour. Journal of Applied Probability, 41(03):601-622, 2004.

Jim Lee. The comovement between output and prices: Evidence from a dynamic conditional correlation garch model. Economics Letters, 91(1):110-116, 2006.

Francis A Longstaff, Sanjay Mithal, and Eric Neis. Corporate yield spreads: Default risk or liquidity? new evidence from the credit default swap market. The Journal of Finance, 60(5): 2213-2253, 2005.

JP Morgan. Reuters (1996). RiskMetrics-Technical Document, 4, 1996. 
Daniel B Nelson. Conditional heteroskedasticity in asset returns: A new approach. Econometrica: Journal of the Econometric Society, pages 347-370, 1991.

Lars Norden and Martin Weber. The co-movement of credit default swap, bond and stock markets: An empirical analysis. European financial management, 15(3):529-562, 2009.

Enrique Sentana. Quadratic arch models. The Review of Economic Studies, 62(4):639-661, 1995.

Yiu K Tse and Albert K C Tsui. A multivariate generalized autoregressive conditional heteroscedasticity model with time-varying correlations. Journal of Business 65 Economic Statistics, 20(3):351-362, 2002.

Yiu Kuen Tse. The conditional heteroscedasticity of the yen-dollar exchange rate. Journal of Applied Econometrics, pages 49-55, 1998.

Christian Walter. Les origines du modèle de marche au hasard en finance. Le modèle de marche au hasard en finance, pages $\mathrm{xx}-\mathrm{xx}, 2013$.

Yu Wei, Yudong Wang, and Dengshi Huang. Forecasting crude oil market volatility: Further evidence using garch-class models. Energy Economics, 32(6):1477-1484, 2010.

Jean-Michel Zakoian. Threshold heteroskedastic models. Journal of Economic Dynamics and control, 18(5):931-955, 1994. 